\title{
Anti free radical \& anti inflammatory effect of rebamipide in chronic gastritis
}

\author{
Marcellus Simadibrata ${ }^{1}$, Ari Fahrial Syam ${ }^{1}$, Aziz Rani ${ }^{1}$, Septelia Inawati Wanandi ${ }^{2}$, Achmad Fauzi ${ }^{1}$, \\ Murdani Abdullah ${ }^{1}$ \\ ${ }^{1}$ Gastroenterology Division, Department of Internal Medicine, Faculty of Medicine, University of Indonesia, Depok, Indonesia \\ ${ }^{2}$ Department of Biochemistry, Faculty of Medicine, University of Indonesia, Jakarta, Indonesia \\ Email: cgono@indosat.net.id
}

Received 11 October 2012; revised 12 November 2012; accepted 19 November 2012

\begin{abstract}
Background/Aim: Free radicals have a role in the development of chronic gastritis. The aim of this study to know the effect and efficacy of rebamipide on free radicals in chronic gastritis. Method: Forty five patients in the division gastroenterology Cipto Mangunkusumo Hospital Jakarta 2009-2010 with moderate and severe gastritis endoscopically were included in this study. Before and after rebamipide treatment the patient were performed endoscopical examination and were taken 5 biopsies for histopathological examination and free radicals (MDA \& Carbonyl Compound) examination. All patients were given rebamipide $100 \mathrm{mg}$ three times a day for $\mathbf{2 8}$ days. Data were analyzed with $t$ test or wilcoxon signed rank test. Exclusion: GERD, Peptic ulcer, PPI treatment, NSAID consumption etc. The symptoms were recorded on day- 0 and day- 28 . The severity symptoms were measured by VAS. Result: The mucosal damage on day- 0 was $2.268 \pm 0.45$ vs day- 28 was $1.707 \pm 0.78(P<0.001)$. The antrum neutrophil: day-0: $0.12 \pm 0.46$ vs day-28: $0.10 \pm 0.37(P=0.710)$ and corpus neutrophil: day- 0 : $0.12 \pm 0.40$ vs day-28: $0.07 \pm 0.26(P=0.421)$. The mean endoscopical mucosal severity score was decreased significantly on day28 compared to day- $0(1.707 \pm 0.78$ vs $2.268 \pm 0.45$; $P<0.05)$. The other histopathological appearances between day- 0 and day-28 were not different. Rebamipide can reduce the mean of MDA from $5.28 \pm$ 3.54 on day-0 to $4.15 \pm 2.71$ on day-28 $(P=0.047)$. The mean of carbonyl compound on day-0 was $4.14 \pm$ 3.01 and on day-28 was $5.12 \pm 2.71(P=0.642)$. Conclusion: Rebamipide significantly reduced the extend of symptoms associated with chronic gastritis. The improvement in symptoms was associated with the decreased of endoscopic severity score and the mean gastric mucosal malondialdehyde (MDA) significantly but not the histopathologic appearance and carbonyl compound.
\end{abstract}

Keywords: Rebamipide; Chronic Gastritis; Histopathologic Severity; MDA; Carbonyl Compound

\section{INTRODUCTION}

Chronic gastritis is an inflammatory condition of the gastric mucosa characterized by elementary lesions, whose extent and distribution are related to their etiology and host response.

Chronic gastritis has a multietiopathogenic factors with dyspeptic syndrome. It is widely accepted that a major underlying factor of this disorder is the generation of free radicals. There is substantial evidence that oxygen derived free radicals play an important role in the pathogenesis of the injury of various tissues, including the digestive system [1]. Furthermore, Helicobacter pylori and non steroidal anti-inflammatory drug (NSAID) are two major causes related to gastric injury. Helicobacter pylori plays an important role in the induction of chronic gastritis and has been accepted that there is a strong association between Helicobacter pylori-associated gastritis and gastric diseases including peptic ulcer and gastric cancer.

Rebamipide is a gastro-protective drug used by patients suffering from gastric ailments and has been widely used as an anti-gastritis and anti-ulcer agent in patients with dyspepsia and gastroesophageal reflux diseases (GERD) [2,3]. Rebamipide is classified as anti-inflammatory agent which will suppress inflammation process, and as anti free-radical agent by inhibiting the release of the free radical, superoxide $\left(\mathrm{O}_{2}^{-}\right)$and also scavenge hydroxyl radical $\left(\mathrm{OH}^{-}\right)$. Rebamipide is one of the most commonly used gastro protective agents in East Asia and had been widely proven that the drug exhibits preventive effects in gastric mucosa by increasing endogenous prostaglandin or by suppressing oxygen free-radicals as well as increasing blood flow. Unlike in Western countries, gastric atrophy is more prominent in Asia, which indicates that mucosal protection is more important than 
mono antiacid therapy.

Helicobacter pylori eradication therapy in patients with functional dyspepsia, gastritis, and gastro esophageal reflux disease remains controversial. Therefore, the therapeutic strategy without $H$. pylori eradication therapy is needed for these symptomatic patients [4,5]. Pre-clinical studies have indicated that rebamipide contributes to the enhancement of the defense mechanism in gastric mucosa, which results from increasing gastric mucus and the stimulation of the production of endogenous prostaglandins without gastric acid suppression. Rebamipide is known to suppress gastric mucosal inflammation, which is thought to be related to its activity in the inhibition of superoxide anion production from neutrophils and scavenging hydroxyl radicals, and in inhibiting interleukin-8 production. Rebamipide appears to be a suitable drug for the treatment of chronic gastritis patients whose symptoms and inflammation in gastric mucosa are not improved by acid-suppressive agents [6,7].

The aim of this study was to evaluate the efficacy and safety of rebamipide for the relief of dyspeptic symptoms due to free radicals and inflammation, and also the improvement in endoscopic and histological appearances in patients suffering from chronic gastritis in Indonesia.

\section{MATERIALS AND METHODS}

\subsection{Patients}

Patients with chronic gastritis by evaluating endoscopic and histological biopsy and with dyspeptic symptoms were enrolled in this study.

Written informed consent was obtained from all participants.

The protocol was approved by the Ethics Committee of the Faculty of Medicine, University of Indonesia.

At screening, upper gastrointestinal endoscopy was performed in all patients so that the presence of endoscopic and histological features of chronic mucosal inflammation could be confirmed. Helicobacter pylori was evaluated by histology and/or rapid urease test.

Patients might also have other symptoms, including stomach heaviness, abdominal fullness, poor appetite, and diarrhea.

Exclusion criteria were: 1) patients who are treated with drugs that may induce gastritis or ulcer or may affect the evaluation before enrolled (NSAIDs, teprenone, sucralfate, PPIs, $\mathrm{H}_{2} \mathrm{RAs}$, antibiotics, mesalazine); 2) chronic alcoholism; 3) drug abuser; 4) contraindicated for endoscopic examination; 5) erosive or ulcerative esophagitis; 6) peptic ulcer; 7) pyloric stenosis; 8) active gastrointestinal bleeding; 9) major absorption disorder; 10) history of gastric surgery; 11) renal disorder (creatinine $>2 \mathrm{mg} / \mathrm{dL}$ ); 12) liver diseases; 13) hematologic disorder; 14) suffering from congestive gastropathy due to liver cirrhosis; 15) congestive heart disease; 16) pregnancy or breast feeding; 17) hypersensitive to rebamipide.

Patients who are under treatment of PPIs or $\mathrm{H}_{2} \mathrm{RAs}$ should undergo wash-out period at least 1 week before enrolled to the study. Only antacid is allowed during the wash-out period.

\subsection{Study Design}

The study was carried out as an open, non-randomized and single group treatment clinical trial performed in Dr. Cipto Mangunkusumo General Hospital, Jakarta, Indonesia between October 2007 and February 2010.

Patients orally received an open-labeled treatment of rebamipide $100 \mathrm{mg}$ three times a day for 4 weeks. Rebamipide used in the current study was an original drug (Mucosta).

\section{EVALUATIONS}

\subsection{Endpoints}

At the end of study, the patients were examined on the basis of their dyspepsia symptoms. Endoscopy was performed to compare endoscopic score and grading of chronic gastritis on day- 0 and day-28.

The primary endpoint of this study was to assess the efficacy of rebamipide in reducing gastric mucosal damage due to free radicals and inflammation. The free radicals were measured accordingly to the malondialdehyde and dicarbonyl compound levels in biochemistry assessment while the latter were measured by the level of mononuclear inflammatory cells and polymerphonuclear neutrophil activity in the laboratory evaluation. The secondary endpoint was to confirm the improvement of dyspeptic symptoms which were measured using the visual analogue scale of the Updated Sydney System [8].

\subsection{Clinical Assessments}

A visual analogue scale-based standard questionnaire was used to investigate and to access the dyspepsia symptoms, such as epigastric pain, nausea, vomiting, anorexia, bloating, belching and early satiety. All of these symptoms were rated by patients using a visual analogue scale from 0 , none, to 10 , worst symptom in day- 0 , day- 7 and day- 28 observation.

\subsection{Endoscopic Evaluation}

The endoscopic appearance of the mucosa was observed and photographed with a video-endoscope. Endoscopic score was expressed in terms of the local endoscopic criteria for evaluation of gastritis and gastric mucosal lesion (Department of Gastroenterology, Cipto Mangunkusumo General Hospital, Faculty of Medicine, Univer- 
sity of Indonesia). Endoscopic was performed before and after treatment (day- 0 and day-28) by 4 endoscopists.

The endoscopic score was expressed from score 0 to score 3: score $0=$ no hyperaemia or erosion (normal), score 1 = mild hyperaemia or mild erosion (mild gastritis), score 2 = mild hyperaemia with moderate erosion or moderate hyperaemia with mild erosion or moderate hyperaemia with moderate erosion (moderate gastritis), score 3 = severe hyperaemia or severe hyperaemia with mild erosion or severe hyperaemia with moderate erosion or severe hyperaemia with severe erosion or moderate hyperaemia with severe erosion or mild hyperaemia with severe erosion (severe gastritis).

\subsection{Laboratory and Histological Evaluation}

During endoscopy, two mucosal biopsy specimens were taken from each of two sites, the corpus and antrum. Giemsa stains for identification of Helicobacter pylori. All specimens were graded for gastritis according to the Updated Sydney System for chronic mononuclear inflammatory cells, polymorphonuclear neutrophil activity, and Helicobacter pylori density. Inflammation and neutrophil activity were classified and graded into four categories: absent, mild, moderate and severe. All the biopsy specimens were reviewed by a pathologist. Hematologic screening such as haemoglobin, erythrocyte, leukocyte, neutrophil, eosinophil, monocytes, lymphocytes, serum creatinine, blood urea nitrogen, AST, ALT, bilirubin were done at day- 0 and day-28. Biochemistry assessment (malondialdehyde and dicarbonyl compound) were done at day-0 and day-28.

\subsection{Safety Assessment}

Patients who are under treatment of PPIs or $\mathrm{H}_{2} \mathrm{RAs}$ should undergo wash-out period at least 1 week before enrolled to the study. Only antacid is allowed during the wash-out period.

Any complaint, adverse drug reaction or adverse events during the study will be recorded in the safety report form in the case study report form.

\subsection{Statistical Analysis}

The data was analyzed with STATA version 9.0. Shapiro wilk normality test was used to describe the data. Then the data was analyzed with dependent t-test or Wilcoxon match paired signed rank test. Statistical significance was defined at the $P<0.05$ level.

\section{RESULTS}

Forty five patients diagnosed with chronic gastritis were enrolled and completed the study. All patients were proven to have dyspeptic symptoms and features of chronic gas- tritis by endoscopy and histology.

There was a significantly improvement of epigastric pain score on day 28 and day 7 after rebamipide compared to day-0 $(P<0.05)$. The score of nausea, anorexia, bloating, belching and early satiety score on day 28 and day 7 after rebamipide was also improved significantly compared to day $0(P<0.05)$. There was no significant improvement of the vomiting score on day 28 or day 7 after rebamipide compared to day 0 (see Table 1).

The mean gastric mucosal malondialdehyde (MDA) was decreased significantly on day-28 rebamipide compared to day- 0 and the mean gastric mucosal dicarbonyl compound (CC) was slightly increased on day-28 rebamipide compared to day-0 but not significant (see Table 2 and Figure 1). The endoscopic mucosal severity score on day-28 was improved significantly compared to day-0 (see Table 2).

Histological features of chronic gastritis according to the updated Sydney system are summarized in Table 2, Figures 2 and 3.

The degree of activity of chronic mononuclear inflammatory cells in both corpus and antrum was higher than polymorphonuclear neutrophil activity in the same area (corpus $1.39 \pm 0.54$ vs $0.12 \pm 0.40$; antrum $1.41 \pm 0.59$ vs $0.12 \pm 0.46)$. There were no differences in mononuclear

Table 1. The score of dyspeptic symptom.

\begin{tabular}{|c|c|c|}
\hline Dyspeptic symptom & Mean \pm SD & $P$ \\
\hline $\begin{array}{l}\text { Epigastric pain } \\
\text { - } \quad \text { Day-0 } \\
\text { - } \text { Day-7 } \\
\text { - } \quad \text { Day-28 }\end{array}$ & $\begin{array}{l}4.15 \pm 2.70 \\
3.00 \pm 2.95 \\
2.00 \pm 2.67\end{array}$ & $\begin{array}{l}0.006 \\
0.003\end{array}$ \\
\hline $\begin{array}{l}\text { Nausea } \\
-\quad \text { Day-0 } \\
\text { - } \quad \text { Day-7 } \\
-\quad \text { Day-28 }\end{array}$ & $\begin{array}{l}3.80 \pm 2.99 \\
2.09 \pm 2.43 \\
1.71 \pm 2.21\end{array}$ & $\begin{array}{l}0.001 \\
0.003\end{array}$ \\
\hline $\begin{array}{l}\text { Vomiting } \\
\text { - } \quad \text { Day-0 } \\
\text { - } \quad \text { Day-7 } \\
\text { - } \quad \text { Day-28 }\end{array}$ & $\begin{array}{l}1.68 \pm 2.63 \\
1.28 \pm 2.58 \\
0.97 \pm 2.16\end{array}$ & $\begin{array}{l}0.387 \\
0.137\end{array}$ \\
\hline $\begin{array}{l}\text { Anorexia } \\
\text { - } \quad \text { Day-0 } \\
\text { - } \quad \text { Day-7 } \\
\text { - } \quad \text { Day-28 }\end{array}$ & $\begin{array}{l}3.43 \pm 3.35 \\
2.52 \pm 2.65 \\
1.94 \pm 2.61\end{array}$ & $\begin{array}{l}0.033 \\
0.001\end{array}$ \\
\hline $\begin{array}{l}\text { Bloating } \\
\text { - } \quad \text { Day-0 } \\
\text { - } \quad \text { Day-7 } \\
\text { - } \quad \text { Day-28 }\end{array}$ & $\begin{array}{l}5.19 \pm 3.45 \\
2.53 \pm 3.13 \\
3.96 \pm 3.42\end{array}$ & $\begin{array}{l}0.001 \\
0.001\end{array}$ \\
\hline $\begin{array}{l}\text { Belching } \\
\text { - } \quad \text { Day-0 } \\
\text { - } \quad \text { Day-7 } \\
\text { - } \quad \text { Day-28 }\end{array}$ & $\begin{array}{l}4.74 \pm 2.83 \\
3.59 \pm 2.79 \\
2.51 \pm 2.60\end{array}$ & $\begin{array}{l}0.001 \\
0.001\end{array}$ \\
\hline $\begin{array}{l}\text { Early satiety } \\
-\quad \text { Day-0 } \\
-\quad \text { Day-7 } \\
-\quad \text { Day-28 }\end{array}$ & $\begin{array}{l}4.83 \pm 3.08 \\
3.95 \pm 2.82 \\
3.35 \pm 3.09\end{array}$ & $\begin{array}{l}0.001 \\
0.001\end{array}$ \\
\hline
\end{tabular}


Table 2. The result of free radical and endoscopic examination.

\begin{tabular}{cccc}
\hline Variable & \multicolumn{3}{c}{$\begin{array}{c}\text { Per protocol } \\
(\mathrm{n}=45)\end{array}$} \\
\hline Univariate: & Day-0 & Day-28 & $P$ \\
\hline $\begin{array}{c}\text { Mean malondialdehyde } \\
\text { (MDA) }\end{array}$ & $5.28 \pm 3.54$ & $4.15 \pm 2.71$ & 0.047 \\
$\begin{array}{c}\text { Mean dicarbonyl } \\
\text { compound (CC) } \\
\text { Endoscopic mucosal } \\
\text { severity score }\end{array}$ & $4.14 \pm 3.01$ & $5.12 \pm 2.71$ & 0.642 \\
\hline
\end{tabular}

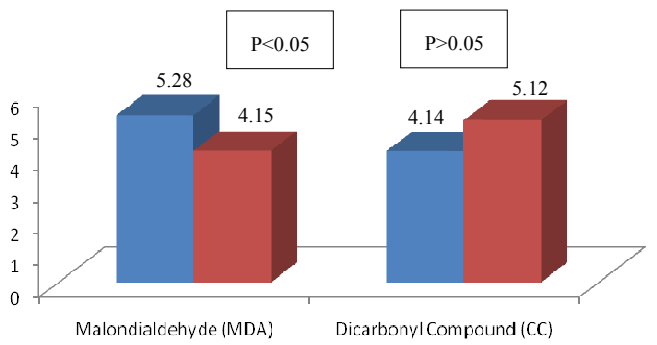

Figure 1. Biochemistry assessment.

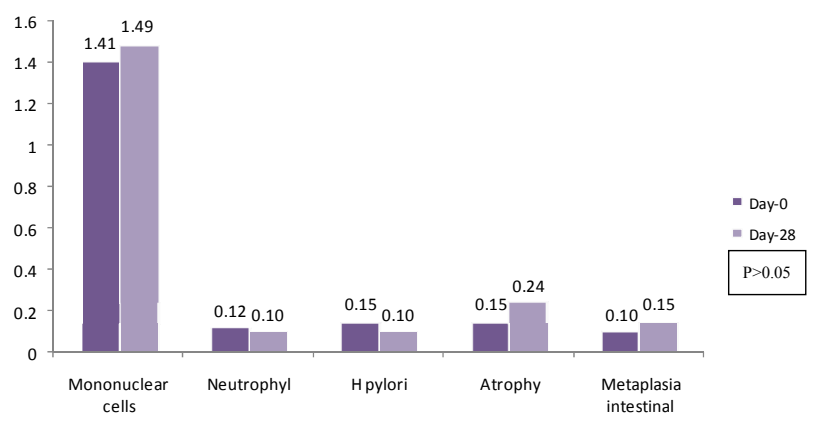

Figure 2. Histopathology assessment of the gastric antrum.

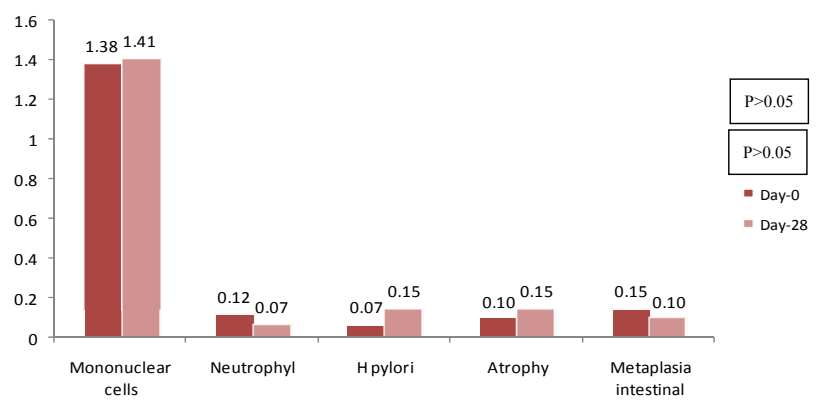

Figure 3. Histopathology assessment of the gastric corpus.

cell infiltration and neutrophil activity between corpus and antrum on day- 0 and day-28 $(P>0.05)$. The density of $H$. pylori colonization in the corpus at day- 0 was lower than in the antrum, with no significant differences before and after treatment $(P>0.05)$. There were no significant changes in atrophy and intestinal metaplasia between corpus and antrum of the stomach before and after treatment $(P>0.05)$ (See Table 3).
Table 3. Histopathological score.

\begin{tabular}{|c|c|c|c|}
\hline Histopathology & Mean score & SD & $\boldsymbol{P}$ \\
\hline $\begin{array}{l}\text { Antrum mononuclear cell } \\
-\quad \text { Day-0 } \\
-\quad \text { Day-28 }\end{array}$ & $\begin{array}{l}1.41 \\
1.49\end{array}$ & $\begin{array}{l}0.59 \\
0.55\end{array}$ & 0.372 \\
\hline $\begin{array}{l}\text { Corpus mononuclear cell } \\
-\quad \text { Day- } 0 \\
-\quad \text { Day- } 28\end{array}$ & $\begin{array}{l}1.38 \\
1.41\end{array}$ & $\begin{array}{l}0.54 \\
0.50\end{array}$ & 0.800 \\
\hline $\begin{array}{l}\text { Antrum neutrophil } \\
-\quad \text { Day-0 } \\
-\quad \text { Day-28 }\end{array}$ & $\begin{array}{l}0.12 \\
0.10\end{array}$ & $\begin{array}{l}0.46 \\
0.37\end{array}$ & 0.710 \\
\hline $\begin{array}{l}\text { Corpus neutrophil } \\
-\quad \text { Day-0 } \\
-\quad \text { Day-28 }\end{array}$ & $\begin{array}{l}0.12 \\
0.07\end{array}$ & $\begin{array}{l}0.40 \\
0.26\end{array}$ & 0.421 \\
\hline $\begin{array}{l}\text { Antrum H. pylori } \\
-\quad \text { Day-0 } \\
-\quad \text { Day-28 }\end{array}$ & $\begin{array}{l}0.15 \\
0.10\end{array}$ & $\begin{array}{l}0.48 \\
0.37\end{array}$ & 0.323 \\
\hline $\begin{array}{l}\text { Corpus H. pylori } \\
-\quad \text { Day-0 } \\
-\quad \text { Day-28 }\end{array}$ & $\begin{array}{l}0.07 \\
0.15\end{array}$ & $\begin{array}{l}0.26 \\
0.48\end{array}$ & 0.262 \\
\hline $\begin{array}{l}\text { Antrum atrophy } \\
-\quad \text { Day-0 } \\
-\quad \text { Day- } 28\end{array}$ & $\begin{array}{l}0.15 \\
0.24\end{array}$ & $\begin{array}{l}0.36 \\
0.49\end{array}$ & 0.253 \\
\hline $\begin{array}{l}\text { Corpus atrophy } \\
-\quad \text { Day- } 0 \\
\text { - } \\
\text { Day- } 28\end{array}$ & $\begin{array}{l}0.10 \\
0.15\end{array}$ & $\begin{array}{l}0.30 \\
0.42\end{array}$ & 0.486 \\
\hline $\begin{array}{l}\text { Antrum intestinal metaplasia } \\
-\quad \text { Day-0 } \\
-\quad \text { Day-28 }\end{array}$ & $\begin{array}{l}0.10 \\
0.15\end{array}$ & $\begin{array}{l}0.30 \\
0.36\end{array}$ & 0.323 \\
\hline $\begin{array}{l}\text { Corpus intestinal metaplasia } \\
-\quad \text { Day- } 0 \\
-\quad \text { Day- } 28\end{array}$ & $\begin{array}{l}0.15 \\
0.10\end{array}$ & $\begin{array}{l}0.48 \\
0.30\end{array}$ & 0.534 \\
\hline
\end{tabular}

\section{DISCUSSION}

Rebamipide, a gastro-protective agent, has been used clinically for the treatment of acute gastritis and peptic ulcer $[9,10]$.

One of the major roles of rebamipide [2-(4chlorobenzoylamino)-3[2(1H)-quinolonin-4-yl] propionic acid], is to stimulate the generation of endogenous prostaglandins in the gastric mucosa and it has been reported to facilitate and accelerate ulcer healing.

Depending on the extensive published studies in vitro or in vivo, this clinical trial represents a reliable result of rebamipide on chronic gastritis. Open-label design had been chosen in this study, because this was a pilot study only and further trials involving larger sample size and longer observation/treatment period with well-controlled and randomized trials are needed.

Rebamipide shows satisfied chronic gastritis-associated symptom attenuation with 4 weeks therapy. Though symptom scores are sometimes subjective and vary between studies, they may provide direct evidence in clinical trials. Rebamipide showed a better effect on symptom attenuation, including epigastric pain, nausea, anorexia, bloating, belching, and early satiety at day-7 and day-28 
compared with day-0 $(P<0.05)$. While symptom of vomitus was not improved at day-7 and day-28 compared to day $0(P>0.05)$. Chitapanarux et al. and Miwa et al. showed that rebamipide can improve the score of dyspepsia symptoms [5,11]. Rebamipide may have an effect on Nitric oxide (NO), and improve these functional symptoms including bloating, belching etc. It has been proven that Nitric oxide (NO) plays multiple roles in inflammation and was found to be an essential mediator of the maintenance of resting blood flow of the gastric mucosa.

The most frequent characteristic of the patients with gastritis was men $51.1 \%$. The mean age of patients in this study was $42.73 \pm 11.52$ years. The mean Body Mass Index (BMI) of the patients in this study was 22.69 \pm 4.45. Jeffery et al. [12] found that chronic gastritis, gastric ulceration and atrophy and Helicobacter pylori infection is associated with low body mass index (BMI).

There was a significant improvement of endoscopic mucosal severity score on day-28 compared to day-0 $(1.707 \pm 0.78$ vs $2.268 \pm 0.45 ; P<0.05)$.

The mean gastric mucosal malondialdehyde (MDA) was decreased significantly on day-28 compared to day-0 $(P<0.05)$. So, in this study, malondialdehyde (MDA) was measured and this result may show relationship between these values and improvement of gastric mucosa. $\mathrm{Du}$ et al. [13] also showed the improvement of endoscopy scores and gastric mucosa appearances and a significant reduction of malondialdehyde (MDA) after administration of rebamipide in chronic erosive gastritis. Everett et al. [14] also described the levels of malondialdehyde in the gastric mucosa in relationship with lipid peroxidation and Helicobacter pylori infection.

The mean gastric mucosal dicarbonyl compound was slightly increased on day-28 compared to day- 0 but not significant $(P>0.05)$.

Although there was a non-significant small increase in dicarbonyl compound levels from day- 0 to day-28 after rebamipide therapy, the level on day-28 was not significantly affecting the effectiveness of rebamipide. This may be explained by other effects of infection that compensate for increased dicarbonyl compound levels, such as carbonyl reactions with proteins including not only lipid peroxidation reactions but also other physiological oxidative stress reactions [15].

In histopathologic assessment, our study demonstrated that the degree of histological gastritis was not different between the corpus and the antrum. There were no significant changes in the histopathologic examination on day-28 compared to day-0 $(P>0.05)$. There were no significant changes in atrophy and intestinal metaplasia between corpus and antrum of the stomach as well $(P>$ 0.05). Chitapanarux et al. [5] has demonstrated that treatment with rebamipide for 8 weeks not only significantly improved the dyspepsia symptoms (epigastralgia, stomach heaviness, abdominal fullness, poor appetite and diarrhea) but also promoted the healing of both endoscopic and histological features of chronic gastritis. The differences of these results to our study may be related to the short term observation period of the treatment duration.

The anti-free radicals and anti-inflammatory properties of rebamipide in chronic gastritis had been proven in some studies and this is only a pilot study with a relatively small sample size and short term observation period to the treatment duration.

Importantly, no serious adverse event was reported during the study period. The data in the current study indicates the safety of rebamipide.

\section{CONCLUSIONS}

In conclusion, rebamipide was effective in healing gastritis and significantly reduced the extend of symptoms associated with chronic gastritis. The improvement in symptoms was associated with the decreased of endoscopic severity score and the mean gastric mucosal malondialdehyde (MDA) significantly but not the histopathologic appearance and carbonyl compound.

The main shortcoming of this pilot study is the relatively small sample size and short term observation period to the treatment duration.

\section{SUGGESTION}

Regarding the relatively small sample size and short term of observation period, further longer duration, well-controlled and randomized trials are warranted in the future.

\section{ACKNOWLEDGEMENTS}

The authors would like to greatly thank Aan Santi and Indri Rizkiyani for their help and assistance in this study. The authors also thank the endoscopic nurses in Cipto Mangun kusumo Hospital for their assistance as well. Credit should also go to P. T. Otsuka Indonesia for supporting and providing the drugs for the study.

\section{REFERENCES}

[1] Santra, A., Chowdhury, A., Chaudhury, S., et al. (2000) Oxidative stress in gastric mucosa in Helicobacter pylori infection. Indian Journal of Gastroenterology, 19, 21-23.

[2] Hayashi, S., Sugiyama, T., Amano, K., Isogai, H., Isogai, E., Aihara, M., et al. (1998) Effect of rebamipide, a novel antiulcer agent, on Helicobacter pylori adhesion to gastric epithelial cells. Antimicrobial Agents and Chemotherapy, 42, 1895-1889.

[3] Urita, Y., Watanabe, T., Maeda, T., Sasaki, Y., Hike, K., Muto, H., et al. (2009) Rebamipide and mosapride enhance pilocarpine-induced salivation. North American Journal of Medical Sciences, 1, 121-124. 
[4] Chey, W.D. and Wong, B.C. (2007) Practice parameters committee of the American College of Gastroenterology: American College of Gastroenterology guideline on the management of Helicobacter pylori infection. American Journal of Gastroenterology, 102, 1808-1825. doi:10.1111/j.1572-0241.2007.01393.x

[5] Chitapanarux, T., Praisontarangkul, O.A. and Lertprasertsuke, N. (2008) An open-labeled study of rebamipide treatment in chronic gastritis patients with dyspeptic symptoms refractory to proton pump inhibitors. Digestive Diseases and Sciences, 53, 2896-2903. doi:10.1007/s10620-008-0255-5

[6] Naito, Y., Yoshikawa, T., Tanigawa, T., et al. (1995) Hydroxyl radical scavenging by rebamipide and related compounds: Electron paramagnetic resonance study. Free Radical Biology \& Medicine, 18, 117-123. doi:10.1016/0891-5849(94)00110-6

[7] Arakawa, T., Kobayashi, K., Yoshikawa, T., Tarnawski, A. (1998) Rebamipide: Overview of its mechanisms of action and efficacy in mucosal protection and ulcer healing. Digestive Diseases and Sciences, 43, 5S-13S.

[8] Rugge, M. and Genta, R.M. (2005) Staging and grading of chronic gastritis. Human Pathology, 36, 228-233. doi:10.1016/j.humpath.2004.12.008

[9] Naito, Y., Yoshikawa, T., Iinuma, S., Yagi, N., Matsuyama, K., Boku, Y., Fujii, T., Yoshida, N., Kondo, M. and Sasaki, E. (1998) Rebamipide protects against indomethacin-induced gastric mucosal injury in healthy volunteers in double-blind, placebo-controlled study. Digestive Diseases and Sciences, 43, 83S-89S.

[10] Higuchi, K., Arakawa, T., Nebiki, H., Uchida, T., Fuji- wara, Y., et al. (1998) Rebamipide prevents recurrence of gastric ulcers without affecting Helicobacter pylori status. Digestive Diseases and Sciences, 43, S99-S106.

[11] Miwa, T., Osada, T., Nagahara, A., Ohsuka, T., Hojo, M., Tomita, T., et al. (2006) Effect of a gastro-protective agent, rebamipide, on symptom improvement in patients with functional dyspepsia: A double-blind placebo-controlled study in Japan. Journal of Gastroenterology and Hepatology, 21, 1826-1831. doi:10.1111/j.1440-1746.2006.04446.x

[12] Jeffery, P.L., McGuckin, M.A. and Linde, S.K. (2011) Endocrine impact of Helicobacter pylori: Focus on ghrelin and ghrelin o-acyltransferase. World Journal of Gastroenterology, 17, 1249-1260. doi:10.3748/wjg.v17.i10.1249

[13] Du, Y., Li, Z., Zhan, X., Chen, J. and Gao, J. (2008) Antiinflammatory effects of rebamipide according to Helicobacter pylori status in patients with chronic erosive gastritis: A randomized sucralfate-controlled multicenter trial in China-STARS study. Digestive Diseases and Sciences, 53, 2886-2895. doi:10.1007/s10620-007-0180-z

[14] Everett, S.M., Singh, R., Leuratti, C. et al. (2001) Levels of malondialdehyde-deoxyguanosine in the gastric mucosa: Relationship with lipid peroxidation, ascorbic acid, and Helicobacter pylori. Cancer Epidemiology, Biomarkers \& Prevention, 10, 369-376.

[15] Naito, Y., Takagi, T., Okada, H., et al. (2009) Impaired gastric ulcer healing in diabetic mice: Role of methylglyoxal. Journal of Physiology and Pharmacology, 60, 123-130. 